\title{
COMMERCIAL POTATO GROWERS' CONTACT WITH INFORMATION SOURCES THROUGH MOBILE PHONE
}

\author{
M. O. Faruk ${ }^{1}$, M. A. Kashem² and M. Z. Rahman² \\ Bandar Upazila, Narayanganj, Bangladesh
}

\begin{abstract}
The objective of the present study was to determine the overall extent of contact through mobile phone to different information sources by commercial potato growers and to explore the relationships between overall extent of contact through mobile phone and their selected characteristics. The study was carried out at Imampura union under Gazaria Upazila of Munshiganj district. Data were collected from a sample of 88 potato growers by using interview schedule during September to October 2011. Appropriate scales were used in order to measure the concerned variables. Correlation test was used to ascertain the relationships between the concerned variables. Majority (71.6 per cent) of the potato growers had very low mobile phone use while 27.3 per cent of the potato growers had low mobile phone use and only 1.1 per cent had medium use with different information sources. Contact with relatives, friends; different market agents, and cold storage manager were the most important mobile phone using contact sources. Potato growers had more contact with other agents (friends and relatives, progressive potato growers etc.) compared to the input dealer and extension agents. Their characteristics such as year of schooling, household size, farm size, annual family income, attitude towards mobile phone use, knowledge on potato production and commercialization of potato had significant positive relationships with the overall contact through mobile phone; while age, organizational exposure, cosmoliteness had no significant relationships with their extent of contact through mobile phone.
\end{abstract}

Key Words: Commercial, Potato growers, Mobile phone, Information source

\section{INTRODUCTION}

There has been considerable interest in the potential role of ICTs (Information and Communication Technologies), particularly mobile phones, in the field of development communication. As of 2008, there were 364 million mobile phones subscriptions in Africa, 460 million in Latin America, and 1.8 billion in Asia (ITU 2008). These figures are all the more impressive in light of the fact that for quite a few developing countries, mobile phone service was not even available as recently as 10 years ago.

1 Agricultural Extension Officer (AEO), Bandar Upazila, Narayanganj, Bangladesh, Department of Agricultural Extension (DAE), Ministry of Agriculture, Government of the People's Republic of Bangladesh

2 Professor, Department of Agricultural Extension Education, Bangladesh Agricultural University, Mymensingh-2202, Bangladesh

* Correspondence author (Email: kashem1953@gmail.com) 
Table 1. Mobile phone subscriptions in the developing world

\begin{tabular}{|c|c|c|c|c|}
\hline \multirow[t]{3}{*}{ Continent } & \multicolumn{4}{|c|}{ Mobile phone subscribers } \\
\hline & \multicolumn{2}{|c|}{ Number of subscriptions (million) } & \multicolumn{2}{|c|}{ Subscriptions per 100 people } \\
\hline & 2003 & 2008 & 2003 & 2008 \\
\hline Africa & 53 & 364 & 6 & 39 \\
\hline Asia & 482 & 1791 & 13 & 46 \\
\hline Latin America & 127 & 460 & 23 & 78 \\
\hline
\end{tabular}

Source: ITU World Telecommunication/ICT Database 2008, Note: Asia includes the Middle East and excludes Hong Kong, Japan and Macao

In recent times, Bangladesh has entered in the information super highway. "e-Krishi", globally known as "e-Agriculture" which is an emerging field where Information and Communication technologies or ICTs (Radio, TV, Cell Phone, PDAs, PCs) are playing a vital and catalytic role in addressing key hindrances to the growth of agriculture such as mismanagement of inputs, inaccessibility to rural finance, ineffective and inadequate extension service, lack of awareness about agro-processing, and insufficient preparedness for natural calamities, among others. In many developing countries, ICTs in agriculture have proven to have helped farmers boost productivity by giving them access to vital information, such as weather forecasts, crop advice and market pricing, empower them by establishing linkages with policy makers and promote growth or agri-businesses and rural enterprises by connecting the country with the international market.

The diffusion of mobile phones into rural areas represents one of the most profound changes in rural Bangladesh and many other developing countries in the past decade (GSM, 2008). Farmers, agricultural processors, and marketers have transitioned from a culture in which there was virtually no telephone service of any kind to one in which mobile phones are now widely utilized among farmers and at rural markets. Thus, far little is known regarding the utility of the mobile phone for the livelihoods of those within resource constrained environments. Therefore, the present study was undertaken in order to ascertain the commercial potato growers' contact with information sources through mobile phone.

\section{METHODOLOGY}

The study was conducted in Gazaria Upazila of Munshiganj district. The researcher selected mobile phone user commercial potato growers on the basis of their production and marketing of potato after family consumption. The study was conducted in six purposively selected neighbouring villages namely Karimkha, Hoglakandi, Bagaikandi, Kalipura, Jashtitola and Mathabangha under Imampura Union. The selected village had a total of 350 populations from which only 88 samples were randomly selected. Thus, the sample comprised of 25 per cent of the total population. The interview schedule was pre-tested with seven mobile phone user potato growers and then final shape was given to the interview schedule according to the experience of pre-test. The pre-test facilitated the researcher to 
examine the suitability of different questions and status of the instrument in general. Data were collected by the researcher himself during 12 September to 15 October, 2011.

The overall extent of contact with information sources through mobile phone was the dependent variable of the study. Selected ten characteristics namely age, year of schooling, household size, farm size, annual family income, organizational exposure, cosmopoliteness, attitude towards mobile phone use, knowledge on potato production and commercialization. The overall mobile phone used by the potato growers was measured on the basis of the overall extent of mobile phone contact with 15 information sources. These 15 mobile phone using information sources were divided into three categories that were selected considering the suggestions from extension experts, supervisory committee and pre-test experience. Among these 15 items, extension agents (3) items, input dealer (3) items and other agents (9) items were present.

A six- point rating scale was used for computing extent of mobile phone use by the potato growers. The scores of $0,1,2,3,4$, and 5 were assigned for no mobile phone use (not even once per season), very low mobile phone use (1-20 times/season), low mobile phone use (21-40 times/season), medium mobile phone use (41-60 times/season), high mobile phone use (61-80 times/season) and very high mobile phone use (>80 times/season), respectively. The scores obtained by a potato grower on each of the fifteen items were added together to determine his score on overall extent of mobile phone use. Thus, the possible scores on overall extent of mobile phone use by the potato growers could range from 0 to 75 , while 0 indicating no use of mobile phone and 75 indicating very high use of mobile phone by a respondent.

\section{FINDINGS AND DISCUSSION}

\section{Socioeconomic background of the potato growers}

Table 1 shows the salient features of the selected characteristics of the potato growers. It was found that 48.9 per cent respondents belonged to middle aged group while 35.2 per cent and 15.9 per cent constituted old and young aged category, respectively. Respondents having year of schooling- secondary, primary, higher education and illiterate were 52.3, 29.6, 13.6 and 4.5 per cent, respectively. The findings indicated that the majority ( 52.3 per cent) of the respondents had medium sized household, 29.5 per cent had large and 18.2 per cent had small household. The highest proportion (i.e.51 per cent) of the potato growers had medium sized farm compared to 41 per cent small and 8 per cent large farms.

The study revealed that 44.3 per cent of the respondents had medium income while 39.8 per cent having small income and 15.9 per cent had very small income. Table 1 revealed that only 10.3 per cent of the respondents in the study area had high organizational exposure while 51.1 per cent respondents had no organizational exposure and the category of both low and medium organizational exposure constituted 19.3 per cent. 


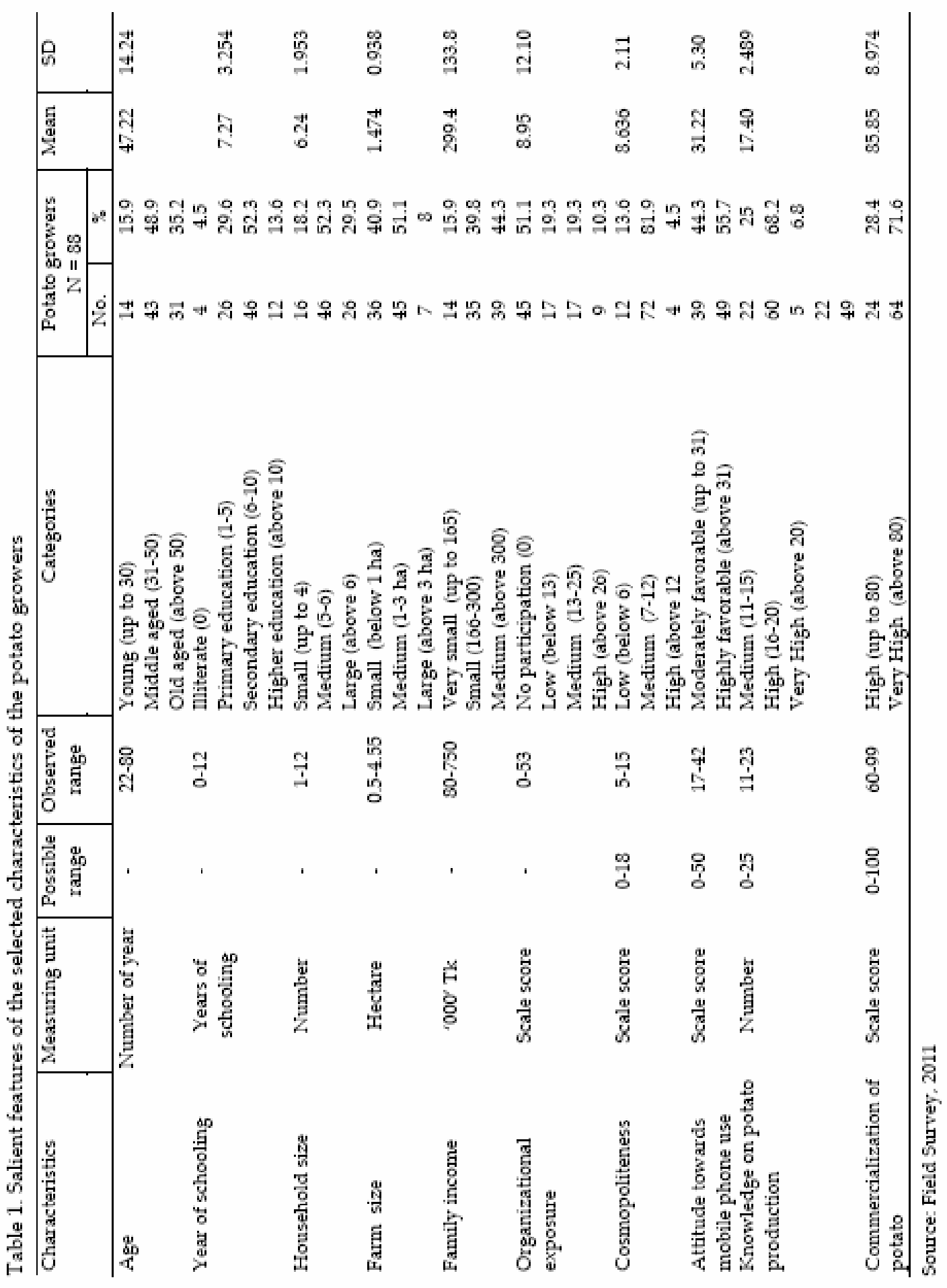


The findings of this study, however, indicated that majority of the respondents (i.e. 81.9 per cent) had medium cosmopoliteness; while 4.5 per cent had high and 13.6 per cent had low cosmopoliteness. The respondents (55.7 per cent) had highly favourable attitude towards mobile phone use, while 44.3 per cent had moderately favourable attitude. Majority of the respondents (68.2 per cent) had high knowledge on potato production, while 25 per cent had medium and 6.8 per cent had very high knowledge on potato production. Table 1 also revealed that majority of the respondents (71.6 per cent) had very high commercialization of potato, while 28.4 per cent had high commercialization of potatoes.

\section{Extent of contact through mobile phone with different information sources Information source-wise extent of mobile phone use}

In present study, potato growers used mobile phone for various purposes and contact with different information sources. As many as 15 contact sources ( 3 extension agents, 3 input dealer and 9 other agents) contributed to the shaping of nature and of mobile phone use by the potato growers. In the event of inclusion of 15 information sources, importance has been given to the all contact sources equally. The extent of use of contact through phone by the potato growers in connection with each source was explained in terms of index. For this, Mobile Phone Use Index (MPUI) regarding each source was determined by using the following formula:

MPUI $=$ MPvh $\times 5+\operatorname{MPh} \times 4+\operatorname{MPm} \times 3+\operatorname{MPl} \times 2+\operatorname{MPvl} \times 1+\operatorname{MPn} \times 0$

Where,

MPUI $=$ Mobile phone Use Index of an individual contact source

MPvh $=$ Number of respondents with very high mobile phone use

$\mathrm{MPh}=$ Number of respondents with high mobile phone use

$\mathrm{MPm}=$ Number of respondents with medium mobile phone use

$\mathrm{MPl}=\mathrm{Number}$ of respondents with low mobile phone use

$\mathrm{MPvl}=$ Number of respondents with very low mobile phone use

MPn $=$ Number of respondents with no mobile phone use

As the total number of the respondent potato growers was 88, the MPUI of each of the information source thus could range from zero (0) to 440. But, to express the MPUI in a meaningful way, it was necessary to convert as Standardize Mobile Phone Use Index (SMPUI) by using the formula in the following manner.

$$
\text { Standardized mobile phone use index }=\frac{\text { Computed MPUI }}{\text { Possible highest MPUI }} \times 100
$$

SMPUI of each of the contact source could range from 0 to 100 , while zero (0) indicated no mobile phone use at all and 100 indicated very high use of mobile phone use by the potato growers. In order to have a clear understanding on the extent of mobile phone use by the potato growers, all the information sources were arranged in rank order (Table 2) according to the SMPUI obtained against each of the information source. 
The SMPUI presented in Table 2 indicated that among 15 information sources, contact with relatives, friends and others ranked first with the highest SMPUI 53.40. Because potato growers can get any information from their closest friends and relatives and they contact more with them for both agricultural and non agricultural purpose.

Table 2. Rank order of the different information sources on the basis of SMPUI

\begin{tabular}{|c|c|c|c|c|c|c|c|c|c|}
\hline \multirow[t]{2}{*}{ Different sources } & \multicolumn{6}{|c|}{ Extent of mobile phone use } & \multirow[t]{2}{*}{ MPUI } & \multirow[t]{2}{*}{ SMPUI } & \multirow{2}{*}{$\begin{array}{l}\text { Rank } \\
\text { order }\end{array}$} \\
\hline & $\begin{array}{l}\text { Very } \\
\text { high }\end{array}$ & High & Medium & Low & $\begin{array}{l}\text { Very } \\
\text { low }\end{array}$ & None & & & \\
\hline Relatives, friends etc & 8 & 16 & 19 & 34 & 6 & 5 & 235 & 53.40 & 1 \\
\hline Other market agents & 4 & 11 & 34 & 17 & 9 & 13 & 219 & 49.7 & 2 \\
\hline Cold storage manager & 0 & 1 & 16 & 22 & 18 & 31 & 114 & 25.9 & 3 \\
\hline Progressive potato growers & 0 & 1 & 4 & 25 & 30 & 28 & 96 & 21.8 & 4 \\
\hline $\begin{array}{l}\text { Sub Assistant Agriculture } \\
\text { Officer (SAAO) }\end{array}$ & 0 & 0 & 4 & 17 & 26 & 41 & 72 & 16.4 & 5 \\
\hline Pesticide dealer & 0 & 0 & 1 & 12 & 42 & 33 & 69 & 15.7 & 6 \\
\hline Fertilizer dealer & 0 & 0 & 1 & 10 & 41 & 38 & 64 & 14.5 & 7 \\
\hline Labour leader & 0 & 0 & 0 & 14 & 32 & 42 & 60 & 13.6 & 8 \\
\hline Potato seed dealer & 0 & 0 & 1 & 11 & 31 & 44 & 56 & 12.7 & 9 \\
\hline $\begin{array}{l}\text { Land owners and tenant } \\
\text { farmers }\end{array}$ & 0 & 0 & 2 & 9 & 28 & 49 & 52 & 11.8 & 10 \\
\hline Transport owner & 0 & 0 & 0 & 7 & 31 & 50 & 45 & 10.2 & 11 \\
\hline $\begin{array}{l}\text { Different banks, NGOs } \\
\text { /money lender }\end{array}$ & 0 & 0 & 0 & 4 & 29 & 55 & 37 & 8.4 & 12 \\
\hline Package businessman & 0 & 0 & 0 & 3 & 27 & 58 & 33 & 7.5 & 13 \\
\hline $\begin{array}{l}\text { Agriculture Extension } \\
\text { Officer (AEO) }\end{array}$ & 0 & 0 & 0 & 1 & 14 & 73 & 16 & 3.6 & 14 \\
\hline $\begin{array}{l}\text { Upazila Agricultural Officer } \\
\text { (UAO) }\end{array}$ & 0 & 0 & 0 & 0 & 7 & 81 & 7 & 1.6 & 15 \\
\hline
\end{tabular}

Different market agents ranked second with the next highest SMPUI 49.7. It became second highest because potato growers need current market information for better commercialization. Every day they contact with whole seller and retailer for up to date market price information.

However, contact with cold storage manager ranked third and contact with progressive growers ranked fourth with their SMPUI of 25.9 and 21.8 respectively. This is because the potato growers' awareness on necessity of their stored potato was more and they used to seek information and suggestion from progressive potato growers on their production. Mobile phone contact with Sub Assistant Agriculture Officer (SAAO) was $5^{\text {th }}$ in rank (SMPUI $=16.4$ ). This might be due to the fact that SAAO is the only field level officer to whom the potato growers may take advice and communicate to address farm problems. 
Mobile phone contact with pesticide dealers, fertilizer dealer, labour leader and contact with seed dealer by the potato growers were ranked as $6^{\text {th }}, 7^{\text {th }}, 8^{\text {th }}$ and $9^{\text {th }}$ respectively. The next contact sources in descending order were land owners and tenant farmers, transport owner, different banks, NGOs /money lender, package businessman, Agriculture Extension Officer (AEO) and Upazila Agriculture Officer (UAO).

\section{Comparative mobile phone use by the potato growers}

In the present study, in order to gets clear understanding about mobile phone using behavior of the potato growers a comparison was made among three categories of mobile phone using information sources i.e. extension agents, input dealer and other agents based on Average Standardized Mobile phone Use Index (ASMPUI). The ASMPUI for each of the aspect was determined by the following formula:

$$
\text { ASMPUI }=\frac{\Sigma \text { SMPUI }}{\mathrm{N}}
$$

Where,

ASMPUI $=$ Average standardized mobile phone use index

$\sum$ SMPUI $=$ Total standardized mobile phone use index obtained from the sources of particular mobile phone use

$\mathrm{N}=$ Number of items of particular mobile phone using agent

However, the ASMPUI for three broad aspects of mobile phone using contact sources has been presented in Table 3.

Table 3. Comparative contact through mobile phone by the potato growers in three broad categories of information sources

\begin{tabular}{c|l|ccc|c}
\hline SI. No. & Categories of information sources & SSMPUI & Number of items (N) & ASMPUI \\
\hline 1 & Extension agents & 21.6 & 3 & 7.2 \\
2 & Input dealer & 42.9 & 3 & 14.3 \\
3 & Other agents & 202.3 & 9 & 22.4 \\
\hline
\end{tabular}

Data revealed in Table 3 that over all extent of contact through mobile phone with extension agents, input dealer and other agents were 7.2, 14.3 and 22.4 respectively. Hence it was clearly observed that potato growers use more mobile phone to communicate with other agents i.e. relatives, friends, different market agents and cold storage manager than input dealer and extension agents.

\section{Overall extent of mobile phone use}

Overall extent of mobile phone use score for the farmers ranged from 0 to 31 against the possible score range of zero (0) to 75 . The mean score for overall extent of mobile phone use by the potato growers was 13.9 with the standard deviation of 4.97 .

Considering the nature of observed score, potato growers were classified into three categories based on their overall extent of contact through mobile phone as very low mobile phone use (up to 15), low mobile phone use (16-30) and medium mobile phone use (above 
30). Distribution of respondents according to mentioned categories has been presented in Table 4.

Table 4. Classification of potato growers according to their overall extent of contact through mobile phone

\begin{tabular}{c|c|l|c|c|c|c}
\hline \multicolumn{2}{c|}{ Range } & \multirow{2}{*}{$\begin{array}{c}\text { Categories according to } \\
\text { mobile phone use }\end{array}$} & \multicolumn{2}{c|}{ Potato growers } & Mean & \multirow{2}{*}{$\begin{array}{c}\text { Standard } \\
\text { deviation }\end{array}$} \\
\cline { 4 - 5 } Possible & Observed & & No. & $\%$ & & 4.97 \\
\hline $0-75$ & $0-31$ & Very low (up to 15) & 63 & 71.6 & 13.9 & \\
& Low (16-30) & 24 & 27.3 & \\
& Medium (above 30) & 1 & 1.1 \\
\cline { 3 - 4 } & Total & 88 & 100 \\
\hline
\end{tabular}

Data in Table 4 revealed that, the highest proportion (71.6 per cent) of the farmers had very low mobile phone use while 27.3 per cent of the farmers had low mobile phone use and only 1 per cent had medium use. However, data also revealed that all of the respondents were mobile phone user but their extent of use of mobile phone was very low to low. Only one potato grower had medium mobile phone use. Overall extent of mobile phone use by the potato growers has been dramatically shown in Fig. 1.

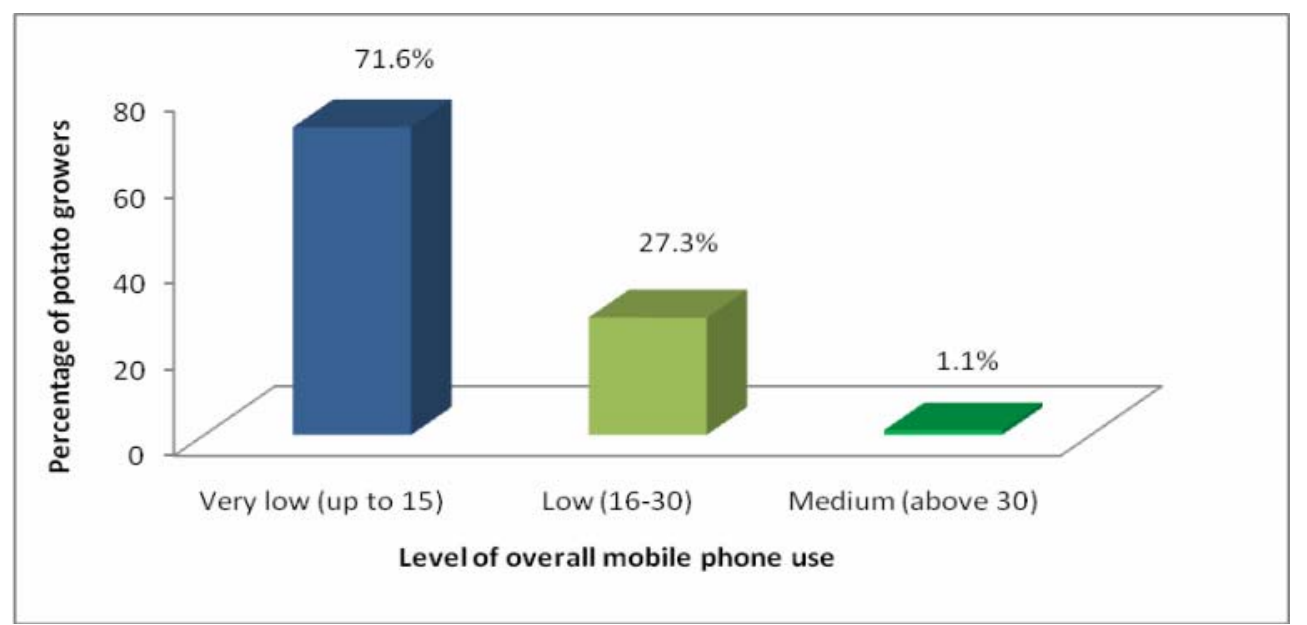

Fig. 1. Bar graph showing overall extent of contact through mobile phone by the commercial potato growers

Relationship between the selected characteristics of the potato growers and their overall extent of contact through mobile phone

The summary of the correlation test between selected characteristics of the potato growers and their extent of mobile phone use has been shown in Table 5. Potato growers' characteristics such as year of schooling, household size, farm size, annual family income, attitude towards mobile phone use, knowledge on potato production and commercialization of potato had significant positive relationships with the overall contact 
through mobile phone; while age, organizational exposure, cosmoliteness had no significant relationships with their extent of contact through mobile phone.

Table 5. Correlation between potato growers' selected characteristics and their overall extent of contact through mobile phone

\begin{tabular}{l|l|c}
\hline \multicolumn{1}{c|}{ Focus variable } & \multicolumn{1}{c}{$\begin{array}{c}\text { Explanatory variables (selected } \\
\text { characteristics) }\end{array}$} & $\begin{array}{c}\text { Correlation coefficient }(\mathrm{r}) \\
\text { with } 86 \mathrm{~d} . \mathrm{f} .\end{array}$ \\
\hline $\begin{array}{l}\text { Overall extent of contact } \\
\text { through mobile phone }\end{array}$ & $\begin{array}{l}\text { Age } \\
\text { Year of schooling }\end{array}$ & -0.081 \\
& Household size & $0.620^{* *}$ \\
& Farm size & $0.418^{* *}$ \\
& Annual family income & $0.641^{* *}$ \\
& Organizational exposure & $0.718^{* *}$ \\
& Cosmopoliteness & 0.186 \\
& Attitude towards mobile Phone use & 0.064 \\
& Knowledge on potato production & $0.712^{* *}$ \\
& Commercialization of potato & $0.527^{* *}$ \\
\hline
\end{tabular}

* Significant at 0.05 level of probability (table value 0.214 ); ${ }^{* *}$ Significant at 0.01 level of probability (table value 0.279 )

Year of schooling was an important factor for mobile phone using behaviour of the potato growers. More education made them aware of using mobile phone for getting quickest information from others as well as to deliver necessary message to others. Therefore, the relationship between the concerned variables was significant; the trend of relationship was positive. This result was not beyond expectation as Chabosso et al. (2009) in their study found that education had significant and positive relationship on mobile phone adoption and use. Barman (2009) and Mukta (2010) also found significant positive relationship between education of the farmers and their overall extent of contact through mobile phone. Significant positive relationship also explored that a large household is using more mobile phone than a small household. Mukta (2010) also found significant positive relationship between family size of the farmers and their overall extent of contact through mobile phone. Based on findings the researcher also found that the farm size of the respondents had significant positive relationship with their extent of mobile phone contact. Ofuoku et al. (2007) also found in their study that farm size of the poultry farmers had significant positive relationship on mobile phone adoption and use. Bhuiyan (1988) and Mukta (2010) also found significant positive relationship between farm size of the farmers and their overall extent of mobile phone use. The result was not beyond expectation as more annual family income is a motivating criterion for the potato growers to adopt quick communicating technology like mobile phone. Moreover, high annual family income encourages one to use mobile phone more than that of potato growers having lower annual family income. Chabosso et al. (2009) in their study also found that family income had significant and positive relationship on mobile phone adoption and use. Barman (2009) and Mukta (2010) 
also found significant positive relationship between family income of the farmers and their overall extent of mobile phone use.

The study revealed that potato growers having more favourable attitude towards mobile phone use had more contact with information sources through mobile phone. Positive attitude always helps the farmers to the quickest adoption of innovation. Barman (2009) also found that attitude towards technology of the farmers had significant positive relationship on mobile phone adoption and use. There also found a significant positive relationship between knowledge and mobile phone use. This indicated that potato growers having more knowledge on potato production have more contact with information sources through mobile phone. Knowledge is power. It helps an individual to increase his understanding and awareness on different aspects of potato production. Barman (2009) also found similar findings in his study.

Considering the above findings, the researcher concluded that potato growers having more commercialization of potato had more contact with information sources through mobile phone. The positive relationship also indicated that high commercialization of potato inspires potato growers to use mobile phone more. Mukta (2010) in her study also found that the commercialization of the farmers had significant positive relationship with their mobile phone using behaviour.

\section{CONCLUSION}

All of the potato growers were the mobile phone users but their extent of contact to different information sources through mobile phone was very low to low. Thus, it is revealed that the use of mobile phone by the potato growers is concentrated to contact with different agricultural agents apart from their contact with family members and relatives.

Findings indicated that year of schooling had significant positive relationship with their overall extent of contact through mobile phone by the potato growers. In the present study, 4.5 per cent of the potato growers had no schooling while almost one third ( 29 per cent) of them had primary schooling. This means that a considerable proportion of the potato growers had no adequate education. Moreover it may be recommended that more non formal education of the farm people is to be increased for the development of communication through mobile phone. A positive significant relationship was also found between knowledge of the potato growers and their overall extent of contact with information sources through mobile phone. This facts leads to conclude that unless attempts are being made by the concerned agencies for increasing knowledge level of the potato growers through non-formal education, they would continue to face difficulties to make contact with information sources through mobile phone.

It was found that there was a significant positive relationship between the respondents' household size and their overall extent of contact through mobile phone with information sources. It revealed that the large household had more communication through mobile phone. The study also found a significant positive relationship between farm size and 
overall contact through mobile phone. Therefore, it may be concluded that potato growers' extent of mobile phone use, to some extent, depends on their household size as well as farm size.

Findings revealed that annual family income of the potato growers had significant positive relationship with their overall extent of contact with information sources through mobile phone. As majority (56 per cent) of the farm families had very low to low family income, but it has significant impact on communication through mobile phone, it may, therefore, be recommended that any attempt to increase the family income of the potato growers has to be taken for increasing their extent of contact with different information sources through mobile phone. It also revealed that commercialization had significant positive relationship with overall extent of contact with different information sources through mobile phone by the potato growers. About three quarters (71.6 per cent) of the potato growers had very high commercialization of potatoes. Hence, it may be recommended to initiate a big potato market vis-à-vis a potato industry through the support of GO or NGOs for the benefit of commercial potato growers.

\section{REFERENCES}

Barman, K. S. 2009. Use of Mobile Phone by the Farmers in Receiving Agricultural Information from the Input Dealers (unpublished Master's thesis). Department of Agricultural Extension Education, Bangladesh Agricultural University, Mymensingh.

Bhuiyan, M. S. I. 1988. Use of Communication Media by the Farmers in the Adoption of Selected Improved Farm Practices in Rice Cultivation (unpublished Master's thesis). Department of Agricultural Extension Education, Bangladesh Agricultural University, Mymensingh.

Chabosso, A., Sork, C \& Zahonogo, Z. 2009. Mobile Telephony Access and Usage in Africa. Paper presented in $3^{\text {rd }}$ Annual Conference on Information and Communication Technologies and Development, Carnegie Mellon University, Education City, Doha, Quatar.

GSM. 2008. How mobile can bring communication to all. Retrieved from http://gsmworld.com/ documents/universal access full report. pdf.

ITU. 2008. Year Book of Statistics. International Telecommunication Union, Telecommunication Service, Geneva.

Mukta, J. N. 2010. Cellphone Using Behaviour of the Farmers with Emphasis on Agricultural Activities (unpublished Master's thesis). Department of Agricultural Extension Education, Bangladesh Agricultural University, Mymensingh.

Ofuoku, A. U., Isife B. I. and Emah, G. N. 2007. Adoption of Mobile Phone among Poultry Farmers in Delta State Nigeria. Journal of Engineering and Applied Sciences, 2 (1): 10-16. 